ture in the future. While some of these potential problems have already been highlighted, ${ }^{8}$ the weakening economy is causing a sharp decline in living standards, mass unemployment, and continued dependence on heavily polluting industries. There is no sign that public health problems will decrease. In this environment the need for public health skills has never been greater.

We thank Dr Theo Miltenburg of the Institute of Applied Social Sciences, Nijmegen, Netherlands; all the staff at Kaunas Medical Academy who helped us gather information and ideas; and in particular Dr Zilvinas Padaiga and Professor Grabauskas for organising the trip. We also thank Dr Caroline Collier of the Department of Health for sponsoring the visit, North West Thames Regional Health Authority for its support, and Drs M McKee and N Black for their comments on previous drafts of the paper.

1 Lithuania health sector review report. Copenhagen: World Health Organisation Regional Office for Europe, 1991.

2 Commission of the European Communities Technical Assistance to EEC's Community Aid and Cooperations Actions in Eastern Europe. Lithuania health sector needs analysis. Cologne: EC, 1991. (Request No 3120.)

3 Chemiauskas G, Pechuuiuliene L. Peculiarities of health care systems in Lithuania. Vilnius: Lithuanian Ministry of Public Health, 1991.

4 Committee of Inquiry into the Future Development of the Public Health Function. Public health in England. London: HMSO, 1988.

Commission of the European Comunities Task Force on Human Resources Education Training and Youth. Tempus scheme for cooperation and mobility in higher education between central leastern Europe and the European Community. Brussels: EC, 1992.

6 World health statistics annual report. Geneva: WHO, 1989:27-149.

7 Lowry S. What's wrong with medical education in Britain. BMF 1992;305: 1277-80.

8 Health sector reform in the former Soviet Union. Lancet 1992;341:210.

\title{
Advice to a Moscow children's hospital
}

\author{
S A McKenzie, O Kurtianyk, M Kidd, D Knowles, H Lipman
}

\begin{abstract}
At the request of the largest children's hospital in Moscow, McKenzie and colleagues made recommendations for improving the service. Restrictions on visiting and fears of contracting illness from nondisposable needles have discouraged the local population from using the hospital. Consequently the hospital is underused and overstaffed. Serious shortages of drugs and surgical supplies compromise care. Fundamental changes are needed in nursing and postgraduate education. The authors encouraged their Russian colleagues to address the health care needs of their local population and to develop family centred care, and they offered training in London.
\end{abstract}

The Russian health care system faces enormous challenges. ${ }^{12}$ Although their scale is different, many of these challenges are no different from those confronting the West-identifying resources, collecting accurate data for planning, and training medical and nursing staff. Policy makers in Russia are advocating administrative and financial autonomy for public institutions. To support their application for such autonomy the Tushino Children's Hospital in Moscow had to identify a project which would improve the quality or range of services it has to offer. To help identify such a project the Tushino Hospital Charitable Trust in London invited us to visit Tushino for a week in September 1992.

We describe here the service at Tushino as we found

Queen Elizabeth Hospital for Children, London E2 8PS

S A McKenzie, consultant paediatrician

O Kurtianyk, director of nursing services

$M$ Kidd, independent adviser

King's Fund College,

London

D Knowles, fellow

Tushinskaya Children's Hospital Charitable Trust, London W1M 7 AF

H Lipman, adviser

Correspondence to: Dr McKenzie.
The range of medical complaints was quite different from that in a children's hospital of comparable size in the West. Most of the patients we saw did not have acute conditions. Other than the few who needed intensive care, we saw no child receiving oxygen and only one receiving intravenous fluids. During the week we saw only one child with respiratory disease. It was difficult to establish why many children were in hospital and what investigations were planned.

To discover where children with acute medical conditions were we visited a second of the four large Moscow children's hospitals, but only surgery and neonatology were practised there. It was at the local polyclinic that we heard how some of these children were cared for. Parents were unwilling for their children to be admitted to hospital because they would be separated from them and because they feared their children might acquire infections from needles. Thus their children were treated at home, which, the doctors thought, was often dangerous. The doctors at the polyclinic were unanimous that "families being allowed to stay with their children" was the most helpful change their hospital could offer.

\section{Arrangements for families at Tushino}

Parents' concern about being separated from their children was intensified by the very restricted arrangements for visiting. Large crowds gathered in the front hall waiting for passes-which could be obtained by bribes-and every day parents would gaze up at the windows of the wards where their children were staying. Moreover, many children in wards for infectious diseases were completely isolated for long periods, and we saw children who were withdrawn and disturbed. Mothers breast feeding infants were among the few parents allowed to stay. Even children in intensive care, who presumably needed extra nursing care, were often totally unattended.

The "medical" reasons given for these restrictions were that parents could bring in or take out infections; that they would not comply with special diets; and by bringing in food parents would undermine doctors' orders (we did notice a full basket being hauled up through a window on a rope and the empty basket being thrown back out). Other reasons were that parents were a nuisance and could be abusive; when they left their child would be upset; and mothers could not stay because they had to work. The hospital staff were also afraid of kidnapping.

There were teachers, and it was clear that high priority was given to continuing education. The playrooms were very tidy and we did not see them in use. 


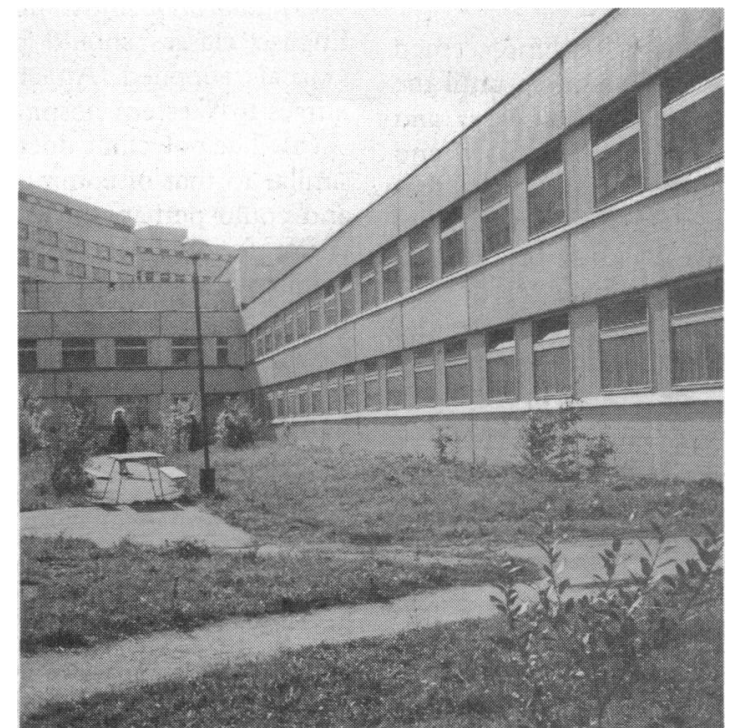

Parents would gaze up at the windows of the wards where their children were staying. . .

\section{Visits to departments}

Paediatric and neonatal intensive care units-There were dedicated intensive care teams in both. Most patients needing ventilatory support had been in road traffic accidents. The four neonatal intensive care units in Moscow, all separate from maternity hospitals, share one transport ventilator in a donated American ambulance. Servicing the ventilator was not difficult but repairing the ambulance was. A shortage of disposable surgical supplies meant there were no cannulas for either peripheral or umbilical access. Subclavian access was the preferred route in both neonates and children. Feeding tubes were used repeatedly. Peroxide used for sterilisation was in short supply, and Hibisol (chlorhexidine), provided by humanitarian aid for hand cleansing, was used instead. Suction catheters were rubber. Russian disposable needles and syringes were available, but donated Western needles did not fit glass syringes. There were no paediatric giving sets, oximeters, or cranial ultrasound facilities. The doctors were very aware of the shortcomings and were clearly providing a remarkable service in the circumstances. Their main concerns were about a lack of trained nurses and hospital acquired infection. Included in the nurses' duties are domestic chores such as floor washing.

Neurology and neurosurgery - Of the 50 or so children few were confined to bed. Several had come from children's homes and had special learning needs"oligophrenics." Neuroradiology was undertaken at another institution. A neurosurgeon, one of 12 in Moscow, summed up his predicament: "No instruments, no drugs, no diagnostic facilities, no radiotherapy...." Parents had to pay for radiotherapy elsewhere.

Infectious diseases-Many children we saw would not have been admitted to hospital in the West. Several had uncomplicated upper respiratory tract infections. The World Health Organisation guidelines for the management of diarrhoea were being followed. Isolation of these patients was rigorous, and children would crouch on the windowsills for long periods looking out to their parents.

Pharmacy and surgical supplies-Water is distilled and intravenous fluids prepared on the premises. Sterilising procedures are on a large scale. Drug shortages have become acute since the breakup of the former Soviet Union, and supplies from non-Russian areas are not assured. Antibiotics and anticonvulsants, the most expensive drugs on the pharmacy budget, were particularly scarce. Drugs such as valerian were used for sedation. Antibiotics provided by humanitarian aid were hoarded. Adult sized tablets were ground and weighed out for infants. The papers used for dispensing these powders were also in short supply. We were told there was sufficient oxygen, anaesthetic gases, and suxamethonium. Dressings and other products made from Central Asian cotton were expensive. There was no modern nebuliser equipment. Drugs were sent to the wards in bulk for dispensing. There was acknowledged abuse and theft.

Microbiology-There was a great mismatch between what was available for antibiotic sensitivity testing and the antibiotics available to prescribe. Staphylococcus aureus was not tested against penicillin or erythromycin. Haemophilus influenzae could not be typed. Gram positive organisms were tested against cefotaxine, ceftazidime, and lincomycin but not against penicillin or chloramphenicol. Because of a shortage of reagents streptococcus could not be cultured. Corynebacterium diphtheriae had been isolated 100 times in the previous three months, probably reflecting a reduction in the availability of vaccine. For sore throats donated carbenicillin or a cephalosporin was used.

Blood bank-A central bank supplies all Moscow. Doctors and parents often donate blood "on the spot" for their own patients. Only one donation in Moscow in the past year had been positive for HIV.

\section{Medical and nursing education}

Although there was a large staff responsible for postgraduate medical education there was no clear programme for doctors. There was no regular occasion set aside for education and little interdisciplinary debate. The library was not catalogued and there were no modern textbooks. We did notice on an administrator's desk a Russian language copy of Family and Child Health, but the young doctors had never seen this journal.

Training for nurses was wholly inadequate and inappropriate for a modern children's service. Nursing is not a prestigious profession in Russia, pay is low, and there is no national regulatory body. Many nurses prefer to work 24 hour shifts and often take a second job. Practical training still includes cupping and leeching. There were no modern teaching aids and little access to books. Because of the very basic training doctors often undertook what in the West would be considered to be nursing tasks.

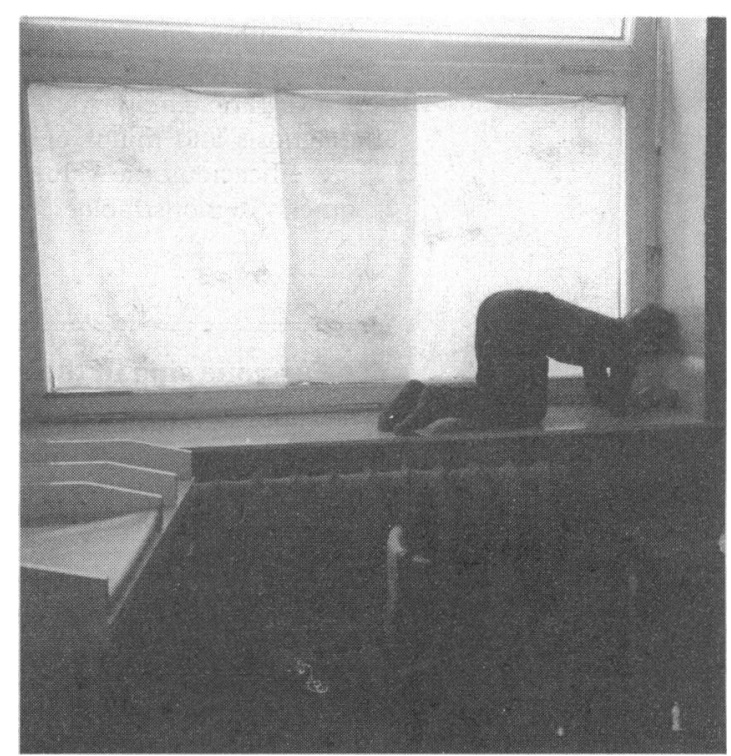

and children would crouch on the windowsills for long periods looking out to their parents 


\section{Recommendations}

The medical conditions treated at Tushino seemed to be similar to those in British hospitals up until the 1950s, with an emphasis on infectious diseases and surgical conditions. The hospital was underused and overstaffed, and many staff feared, realistically, that any change would threaten their employment. Lack of drugs, surgical supplies, investigative procedures, trained nurses, and postgraduate training for doctors hamper progress. We tried to make our recommendations match what could reasonably and quickly be achieved.

(1) The health needs of the children in the area which the hospital serves should be identified before further developments are planned. The hospital, previously a supraregional and supranational institution, has to define its role in local healthcare. This would be an important project worth supporting.

(2) The restrictions in visiting inpatients were clearly working against the admission of children to hospital and were not in the interests of those already admitted. The introduction of family centred care could proceed immediately. We made it clear that there was more to this initiative than just opening the doors. Families would need information about their child's illness, the investigations planned and the reasons for them, the reasons for their child having to stay in hospital, the prognosis, and reasons for isolation if there were any. Staff would need further training so they could give basic information about infectious diseases, the spread of infection, and infection control. They also needed an understanding of anxiety and anger, both in families and in their own day to day practice, and education about the short and long term problems of separation. Doctors and nurses will need help to develop communication skills, and they will have to be prepared to set aside time to devote to the care of the family, especially the distressed family. A Russian version of the recent Audit Commission report would be helpful. ${ }^{3}$

(3) Essential drugs and disposable equipment are crucial for the development of modern medical and surgical procedures. Rather than introduce any new high technology specialties, the existing specialties of neonatology and traumatology should be strengthened. The incidence of road traffic accidents affecting children has increased dramatically in Moscow in recent years. Training in infection control and the proper use of antibiotics is crucial. Those responsible for intensive care units should be encouraged to make lists of their requirements so that sensible requests can be made for further supplies from humanitarian aid. Staff other than nurses should be responsible for cleaning wards.

(4) Day care facilities should be developed for diagnosis and minor operations. Provided treatments are efficacious the value of such a service should be quickly demonstrable.
(5) Education must underpin future development. English classes should be provided and books and journals supplied. Attachments of both doctors and nurses to Western hospitals would be of most benefit.

(6) The polyclinic doctors seemed to be in a position similar to that of community paediatricians in Britain and could perhaps provide home support and supervision for children with conditions which required medical attention but not necessarily hospital admission. Communication with the polyclinics should be strengthened. Savings to the hospital could therefore be made and channelled into caring for acute conditions.

\section{Outcome and discussion}

Western endeavours to advise Russians have been severely criticised. Interest in the Russian predicament has not altogether been altruistic, and it has been emphasised that Westerners should listen to what the Russians want. ${ }^{2}$ The doctors at Tushino had asked for our advice. Our recommendation to introduce family centred care was accepted by the Moscow authorities and Tushino was granted financial autonomy.

Several units at Tushino-now called the Tushinskaya Children's Hospital-have now relaxed visiting restrictions. Not unexpectedly, many staff still need convincing that this is beneficial, though our recommendations were applauded in Pravda": "We are not asking anything from the English...t the English [system] suits us better than the American." The day care centre is in operation and English classes have started.

In keeping with the recommendations of hospital twinning in Europe, ${ }^{5}$ we will offer English speaking doctors and nurses six month attachments in London. Even if a small stipend is needed the funding of such attachments is not insurmountable. We can help our colleagues draw up guidelines for the management of common problems within the context of Russian resources, and such guidelines can be translated. Now that we have seen the Tushino service we are in a better position to advise. Finally, there is an overwhelming need for literature ${ }^{6}$ and we urge our colleagues to save current reviews and appropriate texts.

We are grateful to the Tushino Hospital Trust who made this enterprise possible.

\footnotetext{
1 Baranov AA. Maternal and child health problems in the USSR. Arch Dis Child
}

1992;66:542-5.
2 Delamothe T. Helping Russia. BMF 1992;304:1432-4.

3 Audit Commission: Children First-a study of hospital services. London: Audit

Commission, 1993 (NHS First - a study

4 Arinicheva L. "Pogovori so mnoi, mama" ["Talk to me, mum"]. Moskovskaya Pravda 1992;6 Oct.

5 Richards T. Hospital twinning in Europe. BMF 1992;305:1516-7.

6 Ryan M. Russian report: doctors and health service reform. BMf 1992;304: 101-3.

(Accepted 9 March 1993)

\section{Anyone sing in their sleep?}

Although many forms of nocturnal disturbance-sleep apnoea, somnambulism, sleep talking, night terrorsare well recognised, the medical literature contains no reference to singing in your sleep. Yet the condition is probably not rare. I am aware of three doctors who have experienced the condition. One, on one occasion only, waking the household the night before his music $O$ level by singing some difficult set pieces in the original German. Another used to sing in his sleep until his wife found a way to stop it. A third would trumpet a continuous medley of songs-mainly from the music hall-for most of his adult life while sleeping, for up to 30 minutes at a time. I would be grateful to receive other accounts of sleep singing with details of the content, musicality-if any, cause, and circumstances in which they occur.-EDMUND CRITCHLEY, consultant neurologist, Royal Preston Hospital, Sharoe Green Lane, Preston PR2 4HT

We are pleased to receive submissions of up to 600 words on $A$ paper (or patient or book) that changed my practice, $A$ memorable patient, The one message I would like to leave behind, or related topics. 